\title{
Gene expression profile of DNA binding protein A transgenic mice
}

\author{
HIROSHI TOBITA $^{1,2}$, KAZUNORI KAJINO ${ }^{1}$, KOUICHI INAMI ${ }^{1}$, SAYAKA KANO ${ }^{1}$, \\ MAHMUT YASEN $^{1}$, OSAMU IMAMURA ${ }^{1}$, YOSHIKAZU KINOSHITA ${ }^{2}$ and OKIO HINO ${ }^{1}$ \\ ${ }^{1}$ Department of Pathology, Juntendo University School of Medicine, 2-1-1 Bunkyo-ku, Hongo, Tokyo 113-8421; \\ ${ }^{2}$ Department of Gastroenterology and Hepatology, Shimane University School of Medicine, \\ 89-1 Enya-cho, Izumo-shi, Shimane 693-0021, Japan
}

Received January 2, 2006; Accepted February 17, 2006

\begin{abstract}
We recently reported that the expression of $\mathrm{dbpA}$ (DNA binding protein A) is associated with advanced stages of human hepatocellular carcinoma (HCC) and that its transcription is positively regulated by E2F1, which is also implicated in hepatocarcinogenesis. To study the in vivo effect of $\mathrm{dbpA}$ on hepatocarcinogenesis, we generated the dbpA-transgenic mouse that specifically expressed a transgene in hepatocytes. Here, we studied the effect of dbpA on the expression of other cellular genes by using microarray analyses. The expression profiles from livers of 31- and 32week-old male transgenic mice $[\operatorname{Tg}(+)]$ that did not show any morphological changes and from livers of their male wild-type littermates $[\mathrm{Tg}(-)]$ were compared. Expression differences detected by microarray analyses were validated by reverse transcription-polymerase chain reaction (RT-PCR) using total RNA samples from livers of 3 pairs of $\mathrm{Tg}(+)$ and (-) mice. The 11 up-regulated genes included 7 carcinogenesis-related genes (Igfbp1, Tff3, Hpx, Orm2, Cts1, Plg, Jdp1), and the 9 down-regulated genes included Car3 that is associated with the protection of cells from attack by oxygen radicals. We confirmed that the expression of Igfbp1 (insulin like growth factor binding protein 1) was reduced by siRNA targeting dbpA in the human HCC cell line. In conclusion, our present data suggested that dbpA could be positively involved in carcinogenesis by changing the expression profiles of cellular genes.
\end{abstract}

\section{Introduction}

We recently reported that dbpA (DNA binding protein A) expression is associated with advanced stages of human

Correspondence to: Dr Okio Hino, Department of Pathology, Juntendo University School of Medicine, 2-1-1 Bunkyo-ku, Hongo, Tokyo 113-8421, Japan

E-mail: ohino@med.juntendo.ac.jp

Key words: dbpA, transgenic mouse, hepatocarcinogenesis, microarray analysis, siRNA hepatocellular carcinoma (HCC) (1). The transcription of dbpA is positively regulated by E2F1 (2), which is also implicated in hepatocarcinogenesis (3).

DbpA belongs to the $\mathrm{Y}$ box binding protein family, and the expression of this family member is enhanced in the cellular proliferative states. YB-1 is the prototype member of this family, and is reported to be a prognostic marker of breast cancer (4), ovarian cancer (5), lung cancer (6), thyroid cancer (7), and synovial sarcoma (8). These findings and our recent study on dbpA (1) indicate the significance of Y box binding proteins for the progression of malignant diseases.

To study the in vivo effect of dbpA on hepatocarcinogenesis, we generated dbpA-transgenic ( $\mathrm{Tg}$ ) mice specifically expressing a transgene (mouse-dbpA) in hepatocytes. These mice spontaneously developed liver tumors around 1.5 years old, but did not show any morphological changes in the liver around 30-40 weeks old. In the present study, we examined the effect of $\mathrm{dbpA}$ on the expression of other cellular genes. We performed microarray analysis using total RNA samples from livers of 31- and 32-week-old male dbpA-transgenic mice $[\operatorname{Tg}(+)]$ whose livers were still intact and of their male wildtype littermates $[\operatorname{Tg}(-)]$. Microarray analysis was performed on two different lines of transgenic mice (lines-B and E). The expression of 25 genes was significantly enhanced, whereas the expression of 20 genes was reduced. We validated the result of microarray analysis by RT-PCR using total RNA samples from livers of 3 pairs of $\operatorname{Tg}(+)$ and (-) mice, and finally confirmed the 11 up-regulated and 9 down-regulated genes in $\mathrm{Tg}(+)$ mouse. As many as 7 out of 11 up-regulated genes were genes that might be involved in carcinogenesis (insulinlike growth factor binding protein 1, Igfbp1; trefoil factor 3, Tff3; hemopexin, Hpx; orosomucoid 2, Orm2; cathepsin L, Ctsl; plasminogen, Plg; J domain protein 1, Jdp1). The downregulated genes included carbonic anhydrase 3 (Car3) that is involved in cellular protection from oxygen radicals and MGC 7898 (MGC) whose function is not known. We confirmed that the expression of Igfbp1 was reduced by dbpA-knockdown using siRNA.

In this study, we confirmed that carcinogenesis-associated genes were abundantly expressed in the livers of dbpAtransgenic mice, even in the early stage where there was no morphological abnormality in its liver. 
Table I. dbpA-responsive genes common to both line-B (31 weeks old) and -E (32 weeks old) mice as determined by microarray analysis. ${ }^{\mathrm{a}}$

\begin{tabular}{|c|c|c|c|c|}
\hline \multirow{2}{*}{$\begin{array}{l}\text { GenBank } \\
\text { accession no. }\end{array}$} & \multirow[b]{2}{*}{ Gene names } & \multicolumn{2}{|c|}{ Cy3:Cy5 ratio } & \multirow{2}{*}{$\begin{array}{l}\text { Validation by } \\
\text { RT-PCR }^{\mathrm{b}}\end{array}$} \\
\hline & & B $31 w k$ & E 32wk & \\
\hline NM_011575 & Trefoil factor 3, intestinal (Tff3) & 3.24 & 13.58 & A \\
\hline NM_008341 & Insulin-like growth factor binding protein $1(\operatorname{Igfbp} 1)$ & 8.96 & 7.99 & A \\
\hline NM_009205 & Solute carrier family 3 , member 1 (Slc3a1) & 2.67 & 5.79 & A \\
\hline NM_011016 & Orosomucoid 2 (Orm2) & 8.30 & 5.18 & A \\
\hline NM_007657 & CD9 antigen $(\mathrm{Cd} 9)$ & 3.50 & 4.09 & A \\
\hline NM_009984 & Cathepsin L (Ctsl) & 2.53 & 3.50 & A \\
\hline ВC011246 & Hemopexin (Hpxn) & 4.21 & 3.01 & A \\
\hline NM_008489 & Lipopolysaccharide binding protein (Lbp) & 2.89 & 2.59 & A \\
\hline NM_013888 & $\mathrm{J}$ domain protein 1 (Jdp1-pending) & 4.30 & 2.16 & A \\
\hline NM_010664 & Keratin complex 1, acidic, gene 18 (Krt1-18) & 6.56 & 2.07 & A \\
\hline NM_008877 & Plasminogen $(\mathrm{Plg})$ & 2.11 & 2.11 & A \\
\hline NM_008768 & Orosomucoid 1 (Orm1) & 6.17 & 3.11 & $\mathrm{D}$ \\
\hline NM_031170 & Keratin complex 2 , basic, gene 8 (Krt2-8) & 4.85 & 2.56 & $\mathrm{D}$ \\
\hline NM_133977 & Transferrin (Trf) & 2.97 & 2.54 & $\mathrm{D}$ \\
\hline AB055781 & GlcAT-P mRNA for UDP-glucuronyltransferase-P & 2.17 & 2.47 & $\mathrm{D}$ \\
\hline NM_007752 & Ceruloplasmin $(\mathrm{Cp})$ & 2.92 & 2.43 & $\mathrm{D}$ \\
\hline NM_008498 & LIM homeobox protein 1 (Lhx1) & 2.24 & 2.18 & $\mathrm{D}$ \\
\hline NM_007449 & Angiogenin related protein (Angrp) & 2.93 & 2.15 & $\mathrm{D}$ \\
\hline ВC026388 & Similar to CL1BA protein, clone IMAGE:4188730 & 14.04 & 2.10 & $\mathrm{D}$ \\
\hline NM_008342 & Insulin-like growth factor binding protein 2 (Igfbp2) & 2.04 & 2.08 & $\mathrm{D}$ \\
\hline NM_009864 & Cadherin $1(\mathrm{Cdh} 1)$ & 2.41 & 7.18 & $\mathrm{~N}$ \\
\hline NM_007906 & Eukaryotic translation elongation factor $1 \alpha 2$ (Eef1a2) & 2.99 & 3.36 & $\mathrm{~N}$ \\
\hline NM_013623 & Orosomucoid 3 (Orm3) & 5.92 & 3.15 & $\mathrm{~N}$ \\
\hline X68881 & Emx1 & 2.26 & 2.83 & $\mathrm{~N}$ \\
\hline NM_146818.1 & Olfactory receptor MOR233-12 (MOR233-12) & 2.19 & 2.45 & $\mathrm{~N}$ \\
\hline M29546 & MOD-1 null malic enzyme mRNA & 0.34 & 0.50 & A \\
\hline ВС006692 & Clone MGC:7898 IMAGE:3582717 & 0.23 & 0.45 & A \\
\hline ВC006887 & $\begin{array}{l}\text { Hypothetical Glycerophosphoryl diester phosphodiesterase/Glycosyl } \\
\text { hydrolase, starch-binding domain containing protein }\end{array}$ & 0.34 & 0.45 & A \\
\hline NM_013467 & Aldehyde dehydrogenase family 1, subfamily A1 (Aldh1a1) & 0.45 & 0.33 & A \\
\hline NM_009381 & Thyroid hormone responsive SPOT14 homolog (Rattus) (Thrsp) & 0.33 & 0.25 & A \\
\hline NM_031197 & $\begin{array}{l}\text { Solute carrier family } 2 \text { (facilitated glucose transporter), member } 2 \\
\text { (Slc2a2) }\end{array}$ & 0.23 & 0.24 & A \\
\hline NM_012006 & Cytosolic acyl-CoA thioesterase 1 (Cte1) & 0.12 & 0.22 & A \\
\hline NM_009349 & Thioether S-methyltransferase (Temt) & 0.15 & 0.21 & A \\
\hline NM_007606 & Carbonic anhydrase 3 (Car3) & 0.22 & 0.19 & A \\
\hline NM_007437 & Aldehyde dehydrogenase family 3 , subfamily A2 (Aldh3a2) & 0.15 & 0.48 & $\mathrm{D}$ \\
\hline NM_146718.1 & Olfactory receptor MOR105-5P (MOR105-5P) & 0.41 & 0.47 & $\mathrm{D}$ \\
\hline NM_007757 & Coproporphyrinogen oxidase (Cpo) & 0.42 & 0.44 & $\mathrm{D}$ \\
\hline NM_007377 & Apoptosis-associated tyrosine kinase (Aatk) & 0.39 & 0.38 & $\mathrm{D}$ \\
\hline M61737 & Adipocyte-specific mRNA & 0.36 & 0.36 & $\mathrm{D}$ \\
\hline AK038845 & Hypothetical protein & 0.31 & 0.35 & $\mathrm{D}$ \\
\hline AK002528 & Cytochrome P450, 4a10 & 0.42 & 0.32 & $\mathrm{D}$ \\
\hline NM_007822 & Cytochrome P450, 4a14 (Cyp4a14) & 0.27 & 0.23 & $\mathrm{D}$ \\
\hline BU526246 & cDNA, 5 end & 0.48 & 0.43 & $\mathrm{~N}$ \\
\hline NM_008059 & G0/G1 switch gene 2 (G0s2) & 0.46 & 0.43 & $\mathrm{~N}$ \\
\hline NM_010596 & $\begin{array}{l}\text { Potassium voltage-gated channel, shaker-related subfamily, } \\
\text { member } 7 \text { (Kcna7) }\end{array}$ & 0.37 & 0.37 & $\mathrm{~N}$ \\
\hline
\end{tabular}

${ }^{a}$ Genes with Cy3:Cy5 ratio $>2.0$ or $<0.5$ in both lines are listed. Cy3 represents the signal intensity of Cyanine3-labeled RNA from Tg(+) mice, whereas Cy5 represents that of $\operatorname{Tg}(-)$ mice. ${ }^{b} \mathrm{The}$ microarray result was validated by RT-PCR using 3 pairs of $\operatorname{Tg}(+)$ and $(-)$ mice. Genes of which the microarray result was agreed (A), disagreed (D) by RT-PCR, or those which were not successfully amplified (N), are indicated in the right column. 
Table II. Primar sequences (from 5'- to 3'-ends) used in RT-PCR.

\begin{tabular}{lll}
\hline Gene & \multicolumn{1}{c}{ Sense } & \multicolumn{1}{c}{ Antisense } \\
\hline Mouse & & \\
Tff3 & CCCTCTGGCTAATGCTGTTG & GTGCATTCTGTCTCCTGCAG \\
Igfbp1 & TGCCCGAGTTCCTAACTGTTG & TTCTGGTACACAGGCTCCCTG \\
Orm2 & GCACATGATTCTTGTCATGG & TCTCCTTCTCCAGCTCAAGC \\
Ctsl & CCTAGAAGGACAGATGTTCC & TAGCAACAGAAATAGGCCCC \\
Hps & AGGAAGACAAAGTCTGGGTG & TCCTGATGAGACATAGAGCC \\
Jdp1 & TGGACGCGATACTGAACTAC & GTTCAAGTCTGAGAGACCTG \\
Plg & AAGAACTACTGCCGAAACCC & CACCCAGGATAACCTTGTAG \\
MGC & ATGCTCAACTGTGACATCTC & TGTGACAAATTAGCGACTTCC \\
Car3 & CGCCAATTCCATCTTCACTG & AGCCGTGGTAGGTCCAATAG \\
B-actin & GGCTGTATTCCCCTCCATC & TTTGATGTCACGCACGATTTC \\
Human & & \\
IGFBP1 & & \\
GAPDH & GGCTCGAAGGCTCTCCATG & TATATCTGGCAGTTGGGGTC \\
\hline
\end{tabular}

\section{Materials and methods}

RNA isolation from dbpA-transgenic mouse liver. Total RNA was extracted from livers of 31- and 32-week-old male dbpAtransgenic mice $[\operatorname{Tg}(+)]$ and their male wild-type littermates $[\operatorname{Tg}(-)]$ by the acid guanidinium thiocyanate-phenol-chloroform method (9), using TRIzol (Invitrogen). The method to generate dbpA-transgenic mouse is described elsewhere. Briefly, mouse dbpA cDNA (lacking exon 6) was inserted downstream of the liver-specific SAP (serum amyloid P) promoter in the pGL-SAP vector (10) (a generous gift from Dr K. Yamamura in Kumamoto University). The linearized fragment including the SAP promoter and dbpA cDNA was microinjected into the pronucleus of fertilized eggs of C57BL/6 mice. We obtained the independent two lines ( $\mathrm{B}$ and $\mathrm{E}$ ) in which the transgene was expressed in the liver, and these two were used in the present study.

Microarray analysis of gene expression in dbpA-transgenic mice liver. For the microarray analysis, we used Agilent 22K 60-mer oligonucleotide microarray slides (Agilent, Palo Alto, CA) which covered 22,575 mouse genes. Total RNA samples from livers of male $\operatorname{Tg}(+)$ and $\operatorname{Tg}(-)$ mice $(1 \mu \mathrm{g}$ each) were amplified and labeled with Cyanine3- and Cyanine5-CTP (Perkin-Elmer) to produce labeled cRNA using Agilent low RNA input fluorescent linear amplification kits following the manufacturer's protocol. After the amplification and labeling procedures, the dye-incorporation ratio was determined using a Nanodrop spectrophotometer. The ratios were within 1020 pmol per $\mu \mathrm{g}$ cRNA, the range the manufacturer suggests prior to hybridization. For hybridization, the Agilent 60-mer oligo microarray processing protocol (Rev. 7, SSC Wash/6screw hybridization chamber) was strictly followed. Briefly, $1 \mu \mathrm{g}$ Cy3-labeled $\operatorname{Tg}(+)$ and $1 \mu \mathrm{g}$ Cy5-labeled $\operatorname{Tg}(-)$ samples were mixed and incubated with an Agilent microarray slide for $17 \mathrm{~h}$ using an Agilent in situ hybridization kit following SSC buffer washing. The washed slides were immediately dried using an ultra pure filtered N2 stream in an ozone-free Biobubble. After drying, the slides were scanned using an Agilent G2565AA microarray scanner with the Photo Multiplier Tube Gain (PMT) settings at $70 \%$ or $90 \%$. The data was converted from tif image data to signal using Feature Extraction software (Agilent). The Cy3 [Tg(+)]:Cy5 [Tg(-)] ratio of each labeled cRNA signal was calculated for further analysis.

Reverse transcription-polymerase chain reaction. Reverse transcription (RT)-polymerase chain reaction (PCR) was performed using a Titan One Tube RT-PCR system (Roche) in accordance with the manufacturer's instructions. Reverse transcription and first round amplification using the Titan system involved the preparation of a master-mix 1 and 2 on ice. Mix 1 was comprised of $0.4 \mathrm{mM}$ dNTPs, 80 pmol each of both up- and downstream primers, $10 \mathrm{mM}$ dithiothreitol (DTT), 0.5 or $1 \mu \mathrm{g}$ of extracted total RNA sample from liver, and sterile prechilled deionised water to a final volume of $10 \mu 1$. Mix 2 consisted of $4 \mu 1$ 5X RT-PCR buffer with $3 \mathrm{mM}$ magnesium chloride, $0.4 \mu 1$ enzyme mix of AMV, Taq polymerase and Pwo DNA polymerase, and sterile prechilled deionised water to a final volume of $10 \mu 1$. Mix 1 was distributed into $0.2-\mathrm{ml}$ reaction tubes followed by mix 2 . RT was carried out at $50^{\circ} \mathrm{C}$ for $30 \mathrm{~min}$ followed by $94^{\circ} \mathrm{C}$ for $1.5 \mathrm{~min}$ and first round PCR for 25 or 30 cycles of $94^{\circ} \mathrm{C}$ for $30 \mathrm{sec}, 55$ or $60^{\circ} \mathrm{C}$ for $30 \mathrm{sec}, 68^{\circ} \mathrm{C}$ for $1.5 \mathrm{~min}$ and a final extension at $68^{\circ} \mathrm{C}$ for $10 \mathrm{~min}$. Table II shows the primers for the RT-PCR analysis used in this study. The appropriate cycle ( 25 or 30 cycles) and annealing temperature $\left(55\right.$ or $60^{\circ} \mathrm{C}$ ) for the comparison of the gene expression level between dbpAtransgenic mice and their wild-type littermates was determined for each gene. As an internal control, $B$-actin mRNA for mouse or glyceraldehyde phosphate dehydrogenase (GAPDH) mRNA for human was amplified. RT-PCR products were separated using $1 \%$ agarose gel electrophoresis and visualized with ethidium bromide under an ultraviolet lamp. 
Plasmid construction. Two expression vectors of human dbpA were constructed; one with a full-length cDNA (full$\operatorname{dbpA})$ and the other with a splicing variant lacking exon 6 ( $\triangle$ ex6-dbpA). Each human dbpA cDNA was inserted into the pcDNA3.1(+) vector (Invitrogen). An intact pcDNA3.1(+) vector was used as a negative control in transfection. Transcription from the pcDNA3.1(+) vector is driven by the cytomegalovirus (CMV) immediate early enhancer/promoter.

Small interfering RNA (siRNA) construction. Twenty-onenucleotide, ds/siRNA, and twenty-five-nucleotide, ds/Stealth RNAi constructs targeting human dbpA (accession no: NM_003651) were synthesized (Invitrogen). The sensestrand sequences of these constructs are as follows: no. 1 (Stealth RNAi): 5'-GCCCUCAGUACCGGCAGCGGCG GUU-3' (exon 6), and no. 2: 5'-GAAUAACCCACGGAAAU AUCU-3' (exon 4). A 21-mer double-stranded RNA oligo (B-Bridge) was used as the negative control, of which the sense strand sequence was 5'-AUCCGCGCGAUAGUACG $\mathrm{UA}[\mathrm{dT}][\mathrm{dT}]-3$ ' (3'-overhang).

Transfection of dbpA expression vector and dbpA siRNA. Huh7 cells, derived from human hepatocellular carcinoma, were purchased from Riken Cell Bank (Tsukuba, Japan). Huh7 was cultured in DMEM (Gibco-BRL) supplemented with $10 \% \mathrm{FBS}$ and was maintained in $5 \% \mathrm{CO}_{2}$ at $37^{\circ} \mathrm{C}$. Transient transfection of the human dbpA expression vector and of human dbpA siRNA was performed using FuGENE 6 (Roche) and Lipofectamin 2000 (Invitrogen) respectively. Huh7 cells were plated at $70-80 \%$ confluency in $35-\mathrm{mm}$ cell culture dishes and incubated overnight. Then, the medium was discarded and replaced with antibiotic-free medium. After $12 \mathrm{~h}$, cells were either transfected with $1 \mu \mathrm{g}$ plasmid DNA using FuGENE 6 or with 100 nM RNA oligo using Lipofectamine 2000 reagent following the manufacturer's instructions. The medium was discarded and replaced $24 \mathrm{~h}$ later. Cells were harvested $48 \mathrm{~h}$ after transfection.

Western blotting. Huh7 cells, transfected with the constructs described above, were lysed in a solution containing $2 \%$ SDS, $10 \%$ glycerol, $50 \mathrm{mM}$ Tris- $\mathrm{HCl}$ (pH 6.8), and $100 \mathrm{mM}$ dithiothreitol and boiled. The crude lysates $(10 \mu \mathrm{g})$ were electrophoresed on $10 \%$ Laemmli gels, and transferred to a nitrocellulose membrane, BA85 (Schleicher \& Schuell, NH, USA). The membrane was blocked in $1 \%$ skim-milk in PBS with $0.1 \%$ Tween-20 (PBS-T) for $1 \mathrm{~h}$ at room temperature (rt). The membrane was incubated with $1 \mu \mathrm{g} / \mathrm{ml}$ of anti-dbpA (C-term) (1) in $1 \%$ skim milk in PBS-T for $1 \mathrm{~h}$ at $\mathrm{rt}$. Goat anti-rabbit Ig conjugated to peroxidase labeled-dextran polymer (Envision K4003) (Dako, CA, USA) was used as the secondary antibody (1:50) at $\mathrm{rt}$ for $1 \mathrm{~h}$. dbpA on the membrane was visualized by the ECL detection system (Amersham Biosciences). Monoclonal anti- $\beta$-actin (mouse IgG1 isotype, 1:5000) (Sigma) was used to detect human $\beta$-actin as an internal control.

\section{Results}

Microarray analysis. Two pairs of $\operatorname{Tg}(+)$ and $\operatorname{Tg}(-)$ mice, each from different lines (B and E), were analyzed. Genes

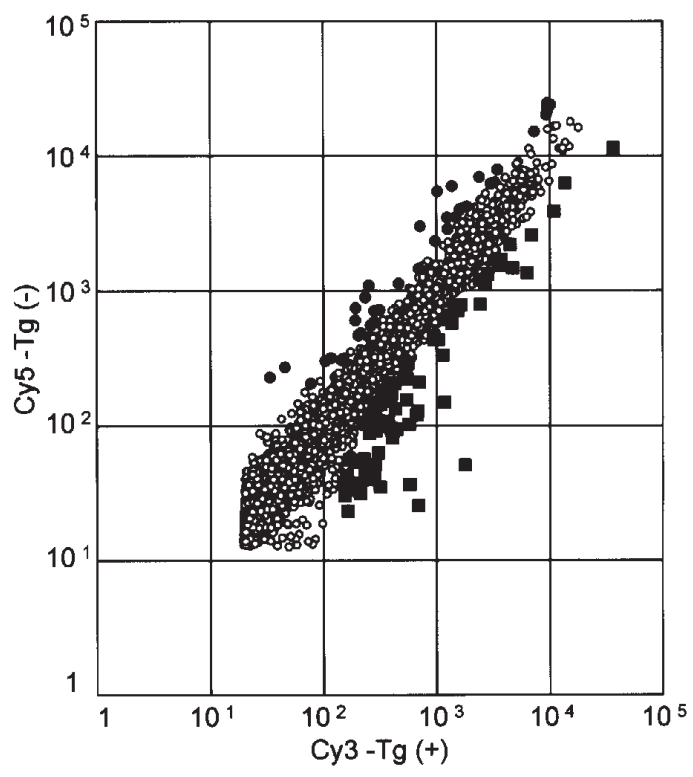

Figure 1. A signal scatter plot of microarray analysis to compare gene expression levels between $\operatorname{Tg}(+)$ and $\operatorname{Tg}(-)$ mice (line E, 32-week-old male). The signal intensities of each gene were quantified using Feature Extraction software (Agilent). The horizontal axis is the scale for the signal intensity of Cyanine3-CTP labeled RNA from a $\mathrm{Tg}(+)$ mouse, whereas the vertical axis is that of Cyanine5-CTP labeled RNA from $\mathrm{Tg}(-)$ mouse. Up-regulated $[\operatorname{Tg}(+)$ to $\operatorname{Tg}(-)$ signal ratio $\geq 2]$, down-regulated (ratio $\leq 0.5$ ), or unchanged (ratio between 0.5 and 2 ) genes were indicated by $\mathbf{\square}, \bullet$, or $\odot$, respectively.

with a $\operatorname{Tg}(+)$ to $\operatorname{Tg}(-)$ signal intensity ratio $\geq 2(\mathrm{P} \leq 0.01)$ were considered up-regulated, whereas genes with a $\operatorname{Tg}(+)$ to $\operatorname{Tg}(-)$ signal intensity ratio $\leq 0.5(\mathrm{P} \leq 0.01)$ were considered downregulated. Fig. 1 shows the comparison of the gene expression levels between $\operatorname{Tg}(+)$ and $\operatorname{Tg}(-)$ 32-week-old mice (line $\mathrm{E}$ ). Table I lists common genes that were up-regulated or downregulated in both lines B and E. The expression of 25 genes was significantly enhanced, whereas the expression of 20 genes was reduced.

$R T-P C R$. The results of microarray analysis were subjected to validation by RT-PCR, using three pairs of male $\mathrm{Tg}(+)$ and $\mathrm{Tg}(-)$ mice including the two pairs used for microarray analysis. In Table I, the 20 or 17 genes, of which the microarray result was agreed or disagreed by RT-PCR, were indicated by (A) or (D) respectively. Eight genes, for which we were not able to amplify the transcript by RT-PCR, were indicated by $(\mathrm{N})$. Eleven of 25 up-regulated, and 9 of 20 down-regulated genes were finally validated by RT-PCR. The 11 up-regulated genes included the following 7 that might be involved in carcinogenesis; Igfbp1 (insulin-like growth factor binding protein 1), Tff3 (trefoil factor 3), Hpx (hemopexin), Orm2 (orosomucoid2), Ctsl (cathepsin L), Plg (plasminogen) and Jdp1 (J domain protein 1). The 9 downregulated genes included Car3 (carbonic anhydrase 3 ) that is associated with the protection of cells from attack by oxygen radicals, and MGC (clone MGC 7898: MGC) whose function is unknown. The representative results of RT-PCR are shown in Fig. 2.

Effect of overexpression or knockdown of dbpA on gene expression in Huh7. To elucidate the effect of $\mathrm{dbpA}$ on the 


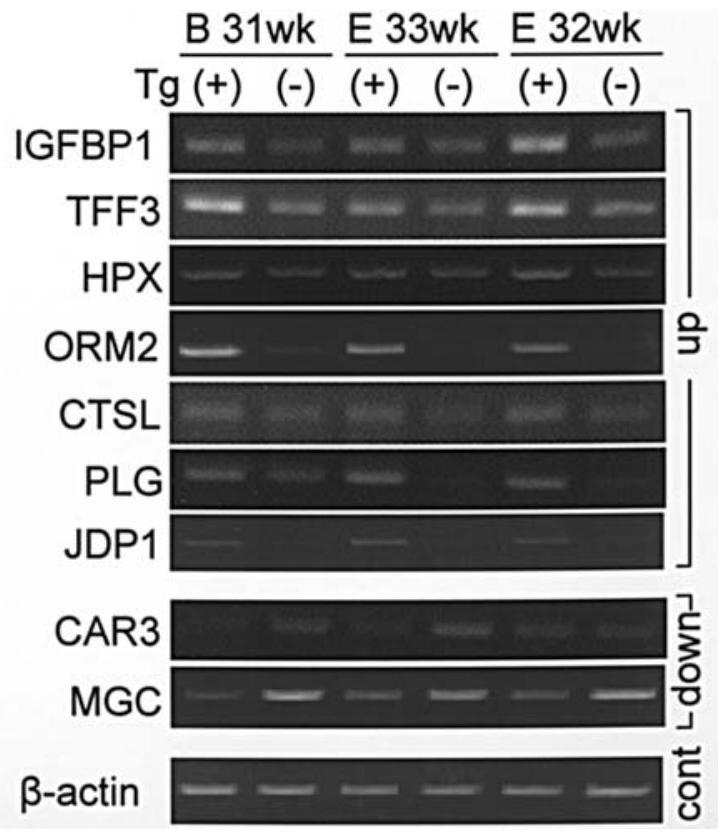

Figure 2. Expression of dbpA-responsive genes. The genes indicated in the left of each panel were amplified by RT-PCR, using total liver RNA from 3 pairs [line B, 31 weeks (wk) old; line E, 33 and 32 weeks old] of $\mathrm{Tg}(+)$ and $\mathrm{Tg}(-)$ male mice. Top seven panels show the expression of up-regulated (up) genes in $\operatorname{Tg}(+)$ mice, and the next two panels show that of down-regulated (down) genes. B-actin was used as an internal control (cont) of RT-PCR.

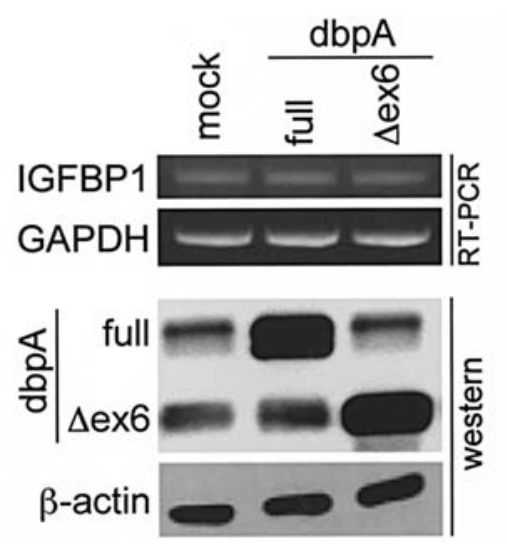

Figure 3. Effect of dbpA overexpression on IGFBP1 in the human HCC cell line (Huh7). The expression level of IGFBP1 and GAPDH (control) was evaluated by RT-PCR (top two panels) and that of dbpA and B-actin (control) was by Western blotting (bottom two panels). Mock, an intact pcDNA3.1 vector as a negative control of transfection; full or $\Delta$ ex6, pcDNA3.1 containing full-length cDNA of dbpA or that lacking exon 6 , respectively.

expression of the genes described above, we transfected Huh7 cells with human dbpA expression vector, and examined the expressional changes of these genes by RT-PCR. Overexpression of human dbpA (full-length dbpA or dbpA splicing variant lacking exon 6) did not up-regulate the expression of any genes, and the representative data relating to IGFBP1 expression is shown in Fig. 4. Then, we transfected siRNA of human dbpA into Huh7 cells and forcibly reduced endogenous dbpA expression (Fig. 4). No. 1 siRNA (for exon 6) preferentially suppressed the expression of the full dbpA transcript, and no. 2 (for exon 4) suppressed both the full transcript and that lacking exon 6. The expression of

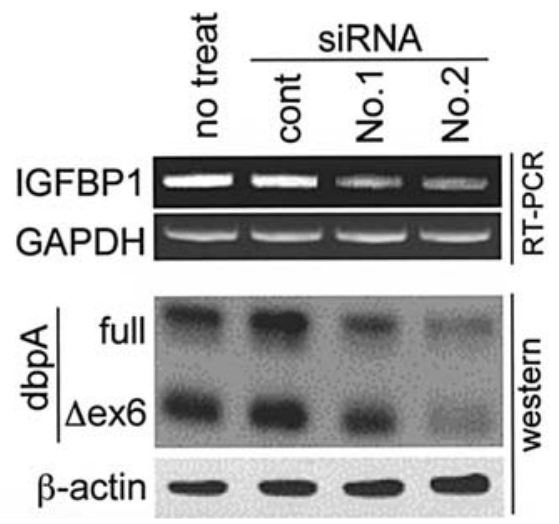

Figure 4. Effect of dbpA knockdown on IGFBP1 in Huh7. The expression level of IGFBP1, GAPDH, dbpA, and B-actin was evaluated as in Fig. 3. Huh7 was transfected with siRNA (control, no. 1 and no. 2) or was not transfected (no treat) with the same medium changes as for the transfected cells.

IGFBP1 was clearly reduced by both siRNA, almost to the same extent. The other genes were not affected by dbpA knockdown (data not shown).

\section{Discussion}

Several studies indicate the role of $\mathrm{Y}$ box binding proteins (YB-1 and dbpA) for the progression of human cancer $(1,4-8)$. Recently, the YB-1 transgenic mouse was reported to develop breast cancer, and YB-1's positive effect on carcinogenesis is demonstrated (11). We generated the dbpA-transgenic mouse using C57BL/6 to study the role of dbpA in hepatocarcinogenesis. Although the number of cases is limited at present, approximately $10 \%$ of these mice spontaneously developed liver tumors around 1.5 years old (data not shown). Currently, we are increasing the number of dbpA-transgenic mice to confirm their susceptibility to hepatocarcinogenesis. These mice did not show any morphological changes in the liver at around 30-40 weeks old. In this report, we studied the effect of $\mathrm{dbpA}$ on the expression of other cellular genes, using total RNA from livers of 31- and 32-week-old dbpA-transgenic mice. We used the morphologically intact liver in order to exclude the non-specific expressional changes caused by the secondary response to carcinogenic steps.

The results of microarray and RT-PCR analyses revealed that expression of Igfbp1, Tff3, Hpx, Orm2, Cts1, Plg and Jdp1 were enhanced, while Car3 was reduced in the livers of dbpA-transgenic mice. Unexpectedly, 7 of 11 up-regulated genes were carcinogenesis-associated and 1 of 9 downregulated genes was associated with the protection of cells from attack by oxygen radicals. In the following paragraphs, we enumerate reports describing these genes as factors associated with carcinogenesis in the liver or other organs. We were not able to find any experimental data or documents to relate the remaining 4 up-regulated and 8 down-regulated genes with carcinogenesis or tumor suppressor functions.

Igfbp1 (insulin-like growth factor binding protein 1) is induced during regeneration of the liver and is implicated in the maintenance of hepatocyte differentiation and metabolism (12). Its expression is elevated in human hepatocellular carcinoma (13). Overexpression of interleukin-6 (IL-6) and 
soluble IL-6 receptor in transgenic mice leads to massive elevation of Igfbp1 and the development of hepatocellular hyperplasia and adenoma (14). Igfbp1 is critical for proper control of the hepatocyte cell cycle, and regulates mitogenic signaling by activating MAPK/ERK (mitogen-activated protein kinase/extracellular signal-regulated kinase) and C/EBP (CCAAT/enhancer binding protein) $\beta$ protein level in vivo (15).

Tff3 (trefoil factor family peptide 3 ) contains a trefoil (three-leafed)-structured domain. It is overexpressed in a wide range of human tumors of skin, breast, urogenital, gastrointestinal tract and liver (16-23) and is thought to induce cancer cell growth. Tff3 overexpression appears to be a frequent event not only in spontaneous (23), transgenicinduced (23), chemically-induced (24) mouse liver tumors, but also in various risk factor-induced human HCC (23).

Both Hpx (hemopexin) and Orm2 (orosomucoid 2) are acute-phase hepatic proteins, and their expression is strongly augmented in experimental hepatocellular carcinoma induced by woodchuck hepatitis B virus (25). Serum ORM2 has also been reported to increase in human hepatocellular carcinoma (26).

CTSL (cathepsin L) is significantly elevated in the sera of cancer patients as compared to normal subjects or liver cirrhosis patients and correlates with the number of malignant lesions (27).

Plg (Plasminogen) supports tumor growth through a fibrinogen-dependent mechanism linked to vascular patency (38). Plg plays a central role in liver repair after acute injury. Its absence severely impairs the clearance of necrotic cell debris and matrix components, resulting in defective repair after acute or chronic injuries (29-32).

Jdp1 ( J domain protein 1) contains DnaJ domain that is a part of a chaperone (protein folding) system. $\mathrm{T}$ antigen is a DnaJ molecular chaperone, and its chaperone activity is required for $\mathrm{T}$ antigen to function in cellular transformation (34).

Car3 (carbonic anhydrase 3 ) is suggested to play a role in scavenging oxygen radicals in cells $(35,36)$. The activities, protein levels and message levels of CAR1, 2, and 3 in HCC are consistently reduced in comparison to the corresponding adjacent normal liver tissue (37). Mice deficient in $\mathrm{CuZn}$ superoxide dismutase (CuZn-SOD) showed increased incidence of neoplastic change in the liver, in which the age-associated reduction in protein and mRNA levels of Car3 was identified (38).

These findings suggest that each of these alterations in gene expression has an important role in the course of carcinogenesis, although the precise mechanism is not clarified. It is noteworthy that such carcinogenesis-related changes in gene expression are caused by overexpression of $\mathrm{dbpA}$ in the morphologically intact liver, suggesting that dbpA might primarily accelerate hepatocarcinogenesis by altering the gene expression of host liver cells.

By the overexpression of $\mathrm{dbpA}$ in Huh7 cells, we tried to examine the effect of $\mathrm{dbpA}$ on the expression levels of the genes described above. Their expression was, however, not affected by the overexpression of dbpA in Huh7. We suspect that this was due to a sufficient amount of endogenous dbpA in Huh7 for it to have maximum effects on the expression of these genes. Generally, immortalized liver cells such as HepG2 or Huh7 highly express $\mathrm{Y}$ box binding proteins (YB-1 and $\mathrm{dbpA}$ ) in the basic level. Therefore, we then tried to forcibly reduce the amount of dbpA in Huh7 by using siRNA, and to observe its effect on the expression levels of genes described above. This knock-down experiment showed that the amount of IGFBP1 mRNA was decreased in accordance with the decrease of dbpA. The data, combined with microarray findings, proved the dependency of IGFBP1/Igfbp1 expression on $\mathrm{dbpA}$, both in immortalized tumor cells and in the intact mouse liver. The result also implicated that the dbpA-IGFBP1/ Igfbp1 relationship may be important both in the initiation and progression of carcinogenesis. The knockdown experiment did not show any effect on the expression levels of genes other than Igfbp1. Although the knockdown experiment did not support the microarray findings, we interpret that the result of microarray analysis using the transgenic mouse liver reflects the physiological state of gene expression more accurately than the result of the overexpression/knockdown experiment using the tumor cell line in which the gene-to-gene relationships are modified as a results of immortalization.

There are two isoforms of $\mathrm{dbpA}$ transcript; one containing all 9 exons, and the other lacking exon 6 . In mouse somatic tissue, only the transcript lacking exon 6 is expressed. Both are expressed only in mouse germline cells. We used mouse cDNA lacking exon 6 for the construction of the transgenic mouse. In humans, both transcripts are expressed in somatic tissue. The reason for this species-specific expressional difference is not known. In our knockdown experiment for human dbpA, no. 1 siRNA reduced the full-length transcript, and no. 2 reduced both the full-length transcript and that lacking exon 6 (Fig. 4). Both siRNAs induced the decreased expression of IGFBP1. Our overexpression/knockdown experiment to demonstrate dbpA's role on Igfbp1/IGFPB1 expression was not complete, in a sense that we could only show that the overexpression of mouse $\mathrm{dbpA}$ transcript lacking exon 6 up-regulated $\operatorname{Igfbp} 1$ in the $\operatorname{Tg}(+)$ mouse, and that the knockdown of full-length transcript down-regulated IGFBP1 in the human cultured cell. It was impossible for us to make the siRNA construct which could specifically knockdown the transcript lacking exon 6 . We suspect that both isoforms could be working in a similar way to regulate the expression of Igfbp1/IGFBP1, i.e. the exon 6 of dbpA could be dispensable for the regulation of Igfbp1/IGFBP1.

In conclusion, we showed that $\mathrm{dbpA}$ influenced the expression of carcinogenesis-associated genes. Our data suggest that $\operatorname{dbpA}$ may induce carcinogenesis by altering cellular gene expression.

\section{Acknowledgements}

This work was supported by a Grant-in-Aid for Cancer Research and Grants-in-Aid for Scientific Research from the Ministry of Education, Culture, Sports, and Science and Technology of Japan and the Ministry of Health, Labor, and Welfare of Japan.

\section{References}

1. Mahmut Y, Kajino K, Kano S, et al: The up-regulation of Ybox binding proteins (DNA binding protein $\mathrm{A}$ and $\mathrm{Y}$-box binding protein-1) as prognostic marker of hepatocellular carcinoma. Clin Cancer Res 11: 7354-7361, 2005. 
2. Arakawa Y, Kajino K, Kano S, et al: Transcription of dbpA, a $\mathrm{Y}$ box binding protein, is positively regulated by E2F1: implications in hepatocarcinogenesis. Biochem Biophys Res Commun 322: 297-302, 2004.

3. Conner IEA, Lammer ER, Omori M, et al: Dual functions of E2F1 in a transgenic mouse model of liver carcinogenesis. Oncogene 19: 5054-5062, 2000.

4. Bargou RC, Jurchott K, Wagener C, et al: Nuclear localization and increased levels of transcription factor YB-1 in primary human breast cancers are associated with intrinsic MDR1 gene expression. Nat Med 3: 447-450, 2001.

5. Kamura T, Yahata H, Amada S, et al: Is nuclear expression of $\mathrm{Y}$ box-binding protein-1 a new prognostic factor in ovarian serous adenocarcinoma? Cancer 85: 2450-2454, 1999.

6. Shibahara K, Sugio K, Osaki T, et al: Nuclear expression of the Y-box binding protein, YB-1, as a novel marker of disease progression in non-small cell lung cancer. Clin Cancer Res 7: 3151-3155, 2001.

7. Ito Y, Yoshida H, Shibahara K, et al: Y-box binding protein expression in thyroid neoplasms: its linkage with anaplastic transformation. Pathol Int 53: 429-433, 2003.

8. Oda Y, Ohishi Y, Saito T, et al: Nuclear expression of Y-boxbinding protein-1 correlates with P-glycoprotein and topoisomerase II $\alpha$ expression, and with poor prognosis in synovial sarcoma. J Pathol 199: 251-258, 2003.

9. Chomczynski P and Sacchi N: Single-step method of RNA isolation by acid guanidinium thiocyanate-phenol-chloroform extraction. Anal Biochem 162: 156-159, 1987.

10. Toyonaga T, Hino O, Sugai S, et al: Chronic active hepatitis in transgenic mice expressing interferon- $\gamma$ in the liver. Proc Natl Acad Sci USA 91: 614-618, 1994.

11. Stephan B, Brigitte R-P, Ellen F, et al: YB-1 provokes breast cancer through the induction of chromosomal instability that emerges from mitotic failure and centrosome amplification. Cancer Res 65: 4078-4087, 2005.

12. Taub R: Liver regeneration 4: transcriptional control of liver regeneration. FASEB J 10: 413-427, 1996.

13. Kondoh N, Wakatsuki T, Ryo A, et al: Identification and characterization of genes associated with human hepatocellular carcinogenesis. Cancer Res 59: 4990-4996, 1999.

14. Maione D, Di Carlo E, Li W, et al: Coexpression of IL-6 and soluble IL-6R causes nodular regenerative hyperplasia and adenomas of the liver. EMBO J 17: 5588-5597, 1998.

15. Leu JI, Crissey MA, Craig LE and Taub R: Impaired hepatocyte DNA synthetic response posthepatectomy in insulin-like growth factor binding protein 1-deficient mice with defects in C/EBP beta and mitogen-activated protein kinase/extracellular signalregulated kinase regulation. Mol Cell Biol 23: 1251-1259, 2003.

16. Hanby AM, McKee P, Jeffery M, et al: Primary musinous carcinomas of the skin express TFF1, TFF3, estrogen receptor and progesterone receptors. Am J Surg Pathol 22: 1125-1131, 1998.

17. Taupin D, Ooi K, Yeomans N and Giraud A: Conserved expression of intestinal trefoil factor in the human colonic adenoma-carcinoma sequence. Lab Invest 75: 25-32, 1996.

18. May FE and Westley BR: Expression of human intestinal trefoil factor in malignant cells and its regulation by oestrogen in breast cancer cells. J Pathol 182: 404-413, 1997.

19. Faith DA, Isaacs WB, Morgan JD, et al: Trefoil factor 3 overexpression in prostatic carcinoma: prognostic importance using tissue microarrays. Prostate 61: 215-227, 2004.

20. Khoury T, Chadha K, Javle M, et al: Expression of intestinal trefoil factor (TFF-3) in hepatocellular carcinoma. Int J Gastrointest Cancer 35: 171-178, 2005.
21. Yio X, Zhang JY, Babyatsky M, et al: Trefoil factor family-3 is associated with aggressive behavior of colon cancer cells. Clin Exp Metastasis 22: 157-165, 2005.

22. Rivat C, Rodrigues S, Bruyneel E, et al: Implication of STAT3 signaling in human colonic cancer cells during intestinal trefoil factor 3 (TFF3) and vascular endothelial growth factor-mediated cellular invasion and tumor growth. Cancer Res 65: 195-202, 2005.

23. Okada H, Kimura MT, Tan D, et al: Frequent trefoil factor 3 (TFF3) overexpression and promoter hypomethylation in mouse and human hepatocellular carcinomas. Int J Oncol 26: 369-377, 2005.

24. Graveel CR, Jatkoe T, Madore SJ, et al: Expression profiling and identification of novel genes in hepatocellular carcinomas. Oncogene 20: 2704-2712, 2001.

25. Darabi A, Gross S, Watabe M, Maiafa M and Watabe K: Differential gene expression in experimental hepatocellular carcinoma induced by woodchuck hepatitis B virus. Cancer Lett 95: 153-159, 1995.

26. Fallet E, Pirisi M, Fabris C, et al: Increase of serum alpha 1-acid glycoprotein despite the decline of liver synthetic function in cirrhotics with hepatocellular carcinoma. Eur J Clin Chem Clin Biochem 31: 407-411, 1993.

27. Leto G, Tumminello FM, Pizzolanti G, et al: Lysosomal cathepsins B and L and Stefin A blood levels in patients with hepatocellular carcinoma and/or liver cirrhosis: potential clinical implications. Oncology 57: 79-83, 1997.

28. Palumbo JS, Talmage KE, Liu H, La Jeunesse CM, Witte DP and Degen JL: Plasminogen supports tumor growth through a fibrinogen-dependent mechanism linked to vascular patency. Blood 102: 2819-2827, 2003.

29. Bezerra JA, Bugge TH, Melin-Aldana H and Sabla G: Plasminogen deficiency leads to impaired remodeling after a toxic injury to the liver. Proc Natl Acad Sci USA 96: 15143-15148, 1999.

30. Bezerra JA, Currier AR, Melin-Aldana H and Sabla G: Plasminogen activators direct regeneration of the liver lobule after acute injury. Am J Pathol 158: 921-929, 2001.

31. Ng VL, Sabla GE, Melin-Aldana $\mathrm{H}$ and Kelley-Loughane: Plasminogen deficiency results in poor clearance of non-fibrin matrix and persistent activation of hepatic stellate cells after an acute injury. J Hepatol 35: 781-789, 2001

32. Pohl JF, Melin-Aldana H, Sabla G, Degen JL and Bezerra JA: Plasminogen deficiency leads to impaired lobular reorganization and matrix accumulation after chronic liver injury. Am J Pathol 159: 2179-2186, 2001.

33. Sullivan CS and Pipas JM: T antigens of simian virus 40 : molecular chaperones for viral replication and tumorigenesis. Microbiol Mol Biol Rev 66: 179-202, 2002.

34. Lii CK, Chai YC, Zhao W, Thomas JA and Hendrich S: Sthiolation and irreversible oxidation of sulfhydryls on carbonic anhydrase III during oxidative stress: a method for studying protein modification in intact cells and tissues. Arch Biochem Biophys 308: 231-239, 1994

35. Raisanen SR, Lehenkari P, Tasanen M, Rahkila P, et al: Carbonic anhydrase III protects cells from hydrogen peroxideinduced apoptosis. FASEB J 13: 513-522, 1999

36. Kuo WH, Chiang WL, Yang SF, Yeh KT, et al: The differential expression of cytosolic carbonic anhydrase in human hepatocellular carcinoma. Life Sci 73: 2211-2223, 2003.

37. Elchuri S, Oberley TD, Qi W, Eisenstein RS, et al: CuZnSOD deficiency leads to persistent and widespread oxidative damage and hepatocarcinogenesis later in life. Oncogene 24: 367-380, 2005. 